\title{
Immunological alterations in individuals exposed to metal(loid)s in the Panasqueira mining area, Central Portugal
}

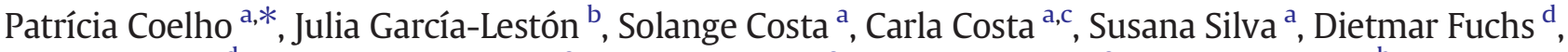 \\ Simon Geisler ${ }^{\mathrm{d}}$, Valentina Dall'Armi ${ }^{\mathrm{e}}$, Roberto Zoffoli ${ }^{\mathrm{e}}$, Stefano Bonassi ${ }^{\mathrm{e}}$, Eduardo Pásaro ${ }^{\mathrm{b}}$, \\ Blanca Laffon ${ }^{\mathrm{b}}$, João Paulo Teixeira ${ }^{\mathrm{a}, \mathrm{c}}$ \\ a National Institute of Health, Environmental Health Department, Rua Alexandre Herculano n321, 4000-055 Porto, Portugal \\ b Toxicology Unit, Department of Psychobiology, University of A Coruña, Campus Elviña s/n, 15071 A Coruña, Spain \\ c Institute of Public Health, University of Porto, Rua das Taipas n135, 4050-600 Porto, Portugal \\ d Division of Biological Chemistry, Biocenter, Innsbruck Medical University, Center for Chemistry and Biomedicine, Innrain 80, 4th Floor, Room M04-313, A-6020 Innsbruck, Austria \\ e Unit of Clinical and Molecular Epidemiology, Istituto di Ricovero e Cura a Carattere Scientifico San Raffaele Pisana, Via di Val Cannuta, 247, 00166 Roma, Italy
}

\section{H I G H L I G H T S}

- Immunotoxic effects were observed in both exposed populations.

- Effects were associated to metal(loid) contamination derived from mine activities.

- Competent authorities need to intervene and help protect exposed populations.

\section{A R T I C L E I N F O}

\section{Article history:}

Received 18 October 2013

Received in revised form 9 December 2013

Accepted 18 December 2013

Available online 11 January 2014

\section{Keywords:}

Immunotoxicity

Metals

Mining activities

Lymphocytes subsets

Neopterin

Tryptophan

\begin{abstract}
A B S T R A C T
Environmental studies performed in Panasqueira mine area (central Portugal) identified high concentrations of several metal(loid)s in environmental media, and individuals environmentally and occupationally exposed showed higher levels of $\mathrm{As}, \mathrm{Cr}, \mathrm{Mg}, \mathrm{Mn}, \mathrm{Mo}, \mathrm{Pb}$ and $\mathrm{Zn}$ in blood, urine, hair and nails when compared to unexposed controls. To evaluate the presence of immunological alterations attributable to environmental contamination, we quantified neopterin, kynurenine, tryptophan, and nitrite concentrations in plasma, and analysed the percentage of several lymphocytes subsets, namely $\mathrm{CD} 3^{+}, \mathrm{CD}^{+}$and $\mathrm{CD} 8^{+} \mathrm{T}$-cells, $\mathrm{CD} 19^{+} \mathrm{B}$-cells, and $\mathrm{CD} 16^{+} 56^{+}$natural killer (NK) cells in a group of individuals previously tested for metal(loid) levels in different biological matrices. The environmentally exposed group had significantly lower levels of $\% \mathrm{CD}^{+}$and higher $\mathrm{CD}^{+} / \mathrm{CD}^{+}$ratios, whereas the occupationally exposed individuals showed significant decreases in $\% \mathrm{CD} 3^{+}$and $\% \mathrm{CD} 4^{+}$, and significant increases in $\% \mathrm{CD} 6^{+} 56^{+}$, when compared to controls. Analysed biomarkers were found to be influenced by age, particularly neopterin, kynurenine and kynurenine to tryptophan ratio (Kyn/Trp) with significantly higher levels in older individuals, and $\% \mathrm{CD} 3^{+}, \% \mathrm{CD}^{+}$and $\% \mathrm{CD} 19^{+}$with significantly lower values in older individuals. Males environmentally exposed showed significantly lower values of $\% \mathrm{CD} 19^{+}$when compared to control females. The concentration of $\mathrm{Pb}$ in toenails was associated to the level of neopterin, kynurenine and Kyn/Trp ratio (all direct), and the concentration of $\mathrm{Mn}$ in blood to the level of \%CD8 ${ }^{+}$, \%CD19 ${ }^{+}$ (both inverse) and $\mathrm{CD}^{+} / \mathrm{CD}^{+}$ratio (direct). Overall our results show that the metal(loid) contamination in Panasqueira mine area induced immunotoxic effects in exposed populations, possibly increasing susceptibility to diseases.
\end{abstract}

(c) 2013 Elsevier B.V. All rights reserved.

\footnotetext{
* Corresponding author. Tel.: +351 966441555 (Mobile); fax: +351 223401149 E-mail addresses: pcscoelho@gmail.com (P. Coelho), jgarciale@gmail.com (J. García-Lestón), solange.costa2@gmail.com (S. Costa), cstcosta@gmail.com (C. Costa), susana.pinho@insa.min-saude.pt (S. Silva), dietmar.fuchs@i-med.ac.at (D. Fuchs), simon.geisler@i-med.ac.at (S. Geisler), valentina.dallarmi@sanraffaele.it (V. Dall'Armi), roberto.zoffoli@sanraffaele.it (R. Zoffoli), stefano.bonassi@sanraffaele.it (S. Bonassi), eduardo.pasaro@udc.es (E. Pásaro), blaffon@udc.es (B. Laffon),jpft12@gmail.com (J.P. Teixeira).
}

\section{Introduction}

Mining activities can adversely affect the health of miners and communities living near mining sites (Coelho et al., 2011b). Several environmental studies performed in the Panasqueira mine in central Portugal showed high concentration of toxic metals and metalloids [= metal(loid)s] in stream sediments, superficial and ground waters from local water courses, road dust, soils, and plants for human consumption cultivated in nearby villages (Ávila et al., 2008; Ferreira 
da Silva et al., 2013; Grangeia et al., 2011; Salgueiro et al., 2008). In order to evaluate the effect of this contamination on populations living nearby and/or working in the mine, biological samples were collected and analysed to quantify the levels of several metal(loid)s - arsenic (As), cadmium $(\mathrm{Cd})$, chromium $(\mathrm{Cr})$, copper $(\mathrm{Cu})$, iron $(\mathrm{Fe})$, mercury $(\mathrm{Hg})$, magnesium $(\mathrm{Mg})$, manganese $(\mathrm{Mn})$, molybdenum (Mo), nickel $(\mathrm{Ni})$, lead $(\mathrm{Pb})$, sulphur $(\mathrm{S})$, selenium $(\mathrm{Se})$, silicon ( $\mathrm{Si})$ and zinc (Zn) (Coelho et al., 2013). Results showed that exposed populations had significantly higher concentrations of $\mathrm{As}, \mathrm{Cr}, \mathrm{Mg}, \mathrm{Mn}, \mathrm{Mo}, \mathrm{Pb}$ and $\mathrm{Zn}$ when compared to unexposed controls. Subjects with the highest concentrations of metal(loid)s were those environmentally exposed, specifically females who presented significantly higher concentrations of the most toxic elements - As, $\mathrm{Cr}$, Mn and $\mathrm{Ni}$.

Most metal(loid)s are toxic to living organisms, even those considered as essential can be toxic when in excess and may cause major health effects, i.e., development retardation, endocrine disruption, kidney damage, immunological and neurologic effects, and several types of cancer (Mudgal et al., 2010). The continuous disturbance of important biochemical processes, such as redox homeostasis, can be associated with chronic pro-inflammatory signalling, leading to induction of proto-oncogenes and/or anti-apoptotic factors, causing a persisting overstimulation of the immune system, thus leading to immunotoxicity (Henkler et al., 2010).

Immunotoxicity is defined as any adverse effect on the structure or function of the immune system, or on other systems as a result of immune system dysfunction (Blank et al., 2000). The susceptibility of the immune system to exposure to metal(loid)s is well-known, although reported effects in exposed populations are conflicting (Cabassi, 2007). This may be mostly attributed to the limited specificity of biomonitoring studies, often not considering the toxicity of the specific element, its concentration, route of exposure, duration of exposure and biologic availability (Lehmann et al., 2011).

Biological parameters measured to assess human immunotoxicity include the count of blood components, antibody-mediated immunity (serum concentrations of immunoglobulins), phenotype analysis of lymphocytes by flow cytometry, among others. More recently Capuron et al. (2009) showed that increased concentrations of inflammatory markers were associated with reduced quality of life in elderly persons, cognitive decline and mood disorders. These alterations influence the metabolism of neurotransmitters and neuroendocrine functions involved in the development of several behaviour symptoms known as sickness behaviour (Capuron et al., 2011). The metabolism of some of these neurotransmitters (e.g. serotonin, norepinephrine, and dopamine) which are synthesized within the brain from their precursors - tryptophan and tyrosine - can be affected by immune activation (Capuron et al., 2011; Schroecksnadel et al., 2006).

Preliminary results from the analyses performed in a small group of individuals living nearby and working in the Panasqueira mine pointed to immunotoxic effects experienced by exposed populations related to the contamination derived from mining activities, but a more robust study with a higher number of subjects and complementary immune markers was needed to confirm these findings (Coelho et al., 2011a, 2012).

The aim of the present study was to evaluate the immunotoxic effects associated with the environmental and occupational exposure to metal(loid) contamination in Panasqueira mine area. Levels of neopterin, tryptophan, kynurenine and nitrite, and percentage of several lymphocytes subsets - T lymphocytes (CD3 ${ }^{+}$ lymphocytes), T helper (Th) lymphocytes (CD4+ lymphocytes), T cytotoxic (Tc) lymphocytes (CD8 ${ }^{+}$lymphocytes), B lymphocytes $\left(\mathrm{CD} 19^{+}\right.$lymphocytes), and natural killer (NK) cells $\left(\mathrm{CD} 16^{+}\right.$and $\mathrm{CD}^{+} 6^{+}$lymphocytes) - were selected as key immune markers. Possible relationships between the levels of immunotoxicity biomarkers and the concentrations of metal(loid)s in biological samples were investigated.

\section{Material and methods}

\subsection{Study population}

The study population consisted of a total of 122 subjects living in the Panasqueira mine district as detailed in Coelho et al. (2013). Forty-one individuals living in villages located in the proximity - within a $6 \mathrm{~km}$ radius - of the mine (S. Francisco de Assis and Barroca do Zêzere) were classified as environmentally exposed (16 males and 25 females), 41 males working in the Panasqueira mine and living in exposed and non-exposed villages were classified as occupationally exposed, and 40 additional subjects (17 males and 23 females) without any exposures to mining activities, or other known toxic exposure, represented the controls. This latter group included individuals living in noncontaminated areas located north-east and west of the mine (Casegas and Unhais-o-Velho, respectively). Control individuals worked mainly in administrative offices and were matched with the environmentally exposed group by age, gender, lifestyle, and smoking habit (categorized as ever/never smokers). Only individuals living in the villages for at least 5 years and aged over 18 years were selected. Health conditions, medical history, medication, diagnostic tests (X-rays, etc.), and lifestyle factors were assessed by means of a questionnaire. Subjects were also interviewed about specific symptoms related to metal(loid) exposure, the presence of chronic respiratory diseases, such as bronchitis; drinking and agricultural water source; agricultural practices, including pesticides usage; and diet. Conditions known to affect the immune system or with a significant effect on any biomarker to be analysed were considered exclusion criteria. All subjects were fully informed about the procedures and the aims of this study, and signed an informed consent form. Approval for this study was obtained from the institutional ethical board of the Portuguese National Institute of Health.

\subsection{Sample collection}

Blood samples were collected by venipuncture in tubes containing ethylenediamine tetraacetic acid (EDTA). Samples were transported under refrigeration and kept at approximately $+4{ }^{\circ} \mathrm{C}$ for analysis of lymphocyte subsets. For quantification of neopterin, tryptophan, kynurenine and nitrite the tubes were centrifuged and the supernatant plasma was collected and stored at $-20{ }^{\circ} \mathrm{C}$ until analysis. All samples were coded and analysed under blind conditions.

\subsection{Analysis of lymphocytes subsets}

The percentages of different lymphocyte subsets, namely $\mathrm{T}$ lymphocytes $\left(\mathrm{CD}^{+}\right.$lymphocytes), T helper (Th) lymphocytes $\left(\mathrm{CD} 4^{+}\right.$lymphocytes), $\mathrm{T}$ cytotoxic (Tc) lymphocytes $\left(\mathrm{CD}^{+}\right.$ lymphocytes), B lymphocytes (CD19+ lymphocytes), and natural killer (NK) cells (CD16 ${ }^{+}$and $\mathrm{CD}^{2} 6^{+}$lymphocytes), were quantified by flow cytometry as described in García-Lestón et al. (2011). Analysis was performed on a FACScalibur flow cytometer using Cell Quest Pro software (Becton Dickinson). A minimum of $10^{4}$ events in the lymphocytes window was acquired.

\subsection{Quantification of neopterin, tryptophan, kynurenine and nitrite in plasma samples}

A commercially available enzyme-linked immunosorbent assay (ELISA) kit (BRAHMS, Hennigsdorf, Germany) was used to determine neopterin concentration in plasma, following the manufacturer's instructions. The limit of detection (LOD) was $2 \mathrm{nmol} / \mathrm{L}$ neopterin. Plasma tryptophan and kynurenine concentrations were measured by a highperformance liquid chromatography (HPLC) methodology with 3nitro-L-tyrosine as internal standard, as previously described (Widner et al., 1997). The extent of tryptophan breakdown was estimated by calculating the kynurenine to tryptophan ratio (Kyn/Trp), expressed in 
$\mu \mathrm{mol}$ kynurenine per mmol tryptophan. LOD was $0.1 \mu \mathrm{mol} / \mathrm{L}$ tryptophan and $0.5 \mu \mathrm{mol} / \mathrm{L}$ kynurenine. In order to estimate nitrite oxide (NO) production, the stable $\mathrm{NO}$ metabolite nitrite $\left(\mathrm{NO}_{2}^{-}\right)$was determined by the Griess reaction assay (Promega, Madison, Wisconsin) (Griess, 1879). LOD was $1.5 \mu \mathrm{mol} / \mathrm{L}$ nitrite. Variation coefficients of all the methods lied between 2 and 10\%.

\subsection{Statistical analysis}

The three study groups were compared according to sociodemographic, i.e., gender, age, village of residence, and years of work in the mine, and lifestyle factors potentially influencing immunotoxicity, i.e., smoking habits. Since populations living in the small villages around the mining site are strongly dependent on agriculture and farming, we included variables such as agricultural practices, pesticides usage, source of water for consumption and agriculture, and frequency of fish and shellfish consumption [as possible sources of metal(loid) contamination] on the multivariable analyses. The Chi-square test was applied for categorical variables and the analysis of variance (ANOVA) was applied for continuous variables. The effect of exposure on the level of immunotoxicity was preliminarily tested with the ANOVA. To achieve a better approximation to the normal distribution, a log-transformation of data was applied to neopterin, tryptophan, kynurenine and nitrite levels, Kyn/Trp ratio and to percentages of the different lymphocyte subsets. A multiple linear regression analysis was performed to estimate the effect of exposure on the log-transformed data. The resulting statistics, i.e., mean ratio, expresses the ratio of the mean value of that specific parameter in the exposed group to the corresponding mean value in the controls; the appropriate $95 \%$ confidence interval is also provided. Adjustment for age and smoking habit was applied to all models and actual confounders were identified and estimations adjusted accordingly. A subanalysis on the control and environmentally exposed population was performed to evaluate the role of gender as a confounder and/or effect modifier.

An ancillary analysis was carried out to assess the effect of metal(loid) concentration on biomarkers of immunotoxicity. The study subjects were divided into three groups according to the tertile distribution of each metal(loid). The resulting three-level factors [one factor for each metal(loid)] were, in turn, fitted to the log-transformed value of immunotoxicity biomarkers in a linear regression model which included age, smoking habits, and model-specific confounders. A logistic regression model was applied to identify the relationship between selected symptoms and environmental and/or occupational exposure. Adjustment for age, smoking habits and model-specific confounders was applied. Spearman rank correlation analyses were carried out between neopterin and tryptophan metabolism substances (kynurenine and Kyn/Trp).

The critical limit for significance was set at $P<0.05$. The statistical software used for the analyses were StataCorp. 2011, Stata Statistical Software: Release 12, College Station, TX: StataCorp LP, and SPSS Inc. Released 2004, SPSS for Windows, Version 13, Chicago, SPSS Inc.

\section{Results}

The general characteristics of the study groups are summarized in Table 1. No significant differences in age and source of water for consumption between the three groups were observed. Difference in the distribution of gender and smoking habits were mostly due to only male composition of the occupationally exposed group, the vast majority smokers. Results concerning the level of immunotoxicity biomarkers in the study groups are presented in Table 2. Significant differences were observed in the univariate analysis for $\% \mathrm{CD} 3^{+}, \% \mathrm{CD}^{+}, \% \mathrm{CD}^{+}$, $\% \mathrm{CD}_{16} 6^{+} 56^{+}$, and $\mathrm{CD} 4^{+} / \mathrm{CD}^{+}$ratio. No significant differences were obtained for \%CD19 ${ }^{+}$and the levels of neopterin, tryptophan, kynurenine, nitrite and Kyn/Trp ratio among the three groups.

When multivariable modelling was applied, levels of neopterin, kynurenine and Kyn/Trp ratio were found to be influenced by age (Table 3), with significantly higher mean ratios (MRs) in older individuals, when compared to the youngest group (25-50 years). No significant effect of exposure or smoking habits was observed on any of these markers, but significant correlations were obtained for neopterin with kynurenine $(r=0.569, P<0.01)$ and $K y n / T r p ~(r=0.616$, $P<0.01$ ). Significant effects of exposure and age were observed on the percentage of the different lymphocyte subsets (Table 4). In the environmentally exposed group we observed MRs significantly lower for \%CD8 ${ }^{+}$ and higher for $\mathrm{CD}^{+} / \mathrm{CD}^{+}$ratio when compared to controls. As for the occupationally exposed population, significant decrease was obtained in $\% \mathrm{CD}^{+}$and $\% \mathrm{CD} 4^{+}$, and significant increase in $\% \mathrm{CD} 16^{+} 56^{+}$. Additionally, MRs of $\% \mathrm{CD}^{+}, \% \mathrm{CD} 8^{+}$and $\% \mathrm{CD} 19^{+}$were significantly lower in older individuals, when compared to the youngest group (25-50 years). No significant effect of smoking habits was observed on any of these markers.

The effect of gender was also investigated excluding the occupationally exposed group, composed only by males. The only parameter significantly influenced by this factor, and only in exposed group, was \%CD $19^{+}$, which showed a significantly lower MR in males from the

Table 1

Description of the study population from the Panasqueira mine area.

\begin{tabular}{|c|c|c|c|c|}
\hline Variable & Controls & Environmentally exposed & Occupationally exposed & $P$-value \\
\hline Total & 40 & 41 & 41 & \\
\hline Duration of work (years, current miners) ${ }^{a}$ & - & - & $25.07 \pm 7.07$ & \\
\hline \multicolumn{5}{|l|}{ Village } \\
\hline S. Francisco de Assis & $0(0 \%)$ & $19(46 \%)$ & $9(22 \%)$ & $<0.001^{\mathrm{b}}$ \\
\hline Barroca do Zêzere & $0(0 \%)$ & $22(54 \%)$ & $8(19 \%)$ & \\
\hline Unhais-o-Velho & $24(60 \%)$ & $0(0 \%)$ & $24(59 \%)$ & \\
\hline Casegas & $16(40 \%)$ & $0(0 \%)$ & $0(0 \%)$ & \\
\hline \multicolumn{5}{|l|}{ Gender } \\
\hline Females & $23(59 \%)$ & $25(61 \%)$ & $0(0 \%)$ & $<0.001^{\mathrm{b}}$ \\
\hline Males & $17(43 \%)$ & $16(39 \%)$ & $41(100 \%)$ & \\
\hline Age (years) ${ }^{a}$ & $56.6 \pm 12.58$ & $61.71 \pm 13.5$ & $62.05 \pm 7.57$ & $0.063^{\mathrm{c}}$ \\
\hline \multicolumn{5}{|l|}{ Smoking habit } \\
\hline Never smokers & 25 (62\%) & $32(78 \%)$ & $16(39 \%)$ & $0.001^{\mathrm{b}}$ \\
\hline Ever smokers & $15(38 \%)$ & $9(22 \%)$ & $25(61 \%)$ & \\
\hline \multicolumn{5}{|l|}{ Water consumption } \\
\hline Bottled water & $2(5 \%)$ & $3(7 \%)$ & $4(10 \%)$ & $0.714^{\mathrm{b}}$ \\
\hline Tap water & $20(51 \%)$ & $23(56 \%)$ & $17(41 \%)$ & \\
\hline Spring water & 17 (44\%) & $15(37 \%)$ & $20(49 \%)$ & \\
\hline
\end{tabular}

Mean \pm standard deviation

b Chi-square test.

c ANOVA test. 
Table 2

Levels of immunotoxicity biomarkers in the study groups.

\begin{tabular}{|c|c|c|c|c|c|c|c|}
\hline \multirow[t]{2}{*}{ Variable } & \multirow[b]{2}{*}{$\mathrm{N}$} & \multirow{2}{*}{$\frac{\text { Controls }}{\text { Mean } \pm \text { SD }}$} & \multirow[b]{2}{*}{$\mathrm{N}$} & \multirow{2}{*}{$\frac{\text { Environmentally exposed }}{\text { Mean } \pm \text { SD }}$} & \multirow[b]{2}{*}{$\mathrm{N}$} & \multirow{2}{*}{$\frac{\text { Occupationally exposed }}{\text { Mean } \pm \text { SD }}$} & \multirow[b]{2}{*}{$P$-value ${ }^{\mathrm{a}}$} \\
\hline & & & & & & & \\
\hline Neopterin (nmol/L) & 24 & $4.4 \pm 0.8$ & 22 & $4.8 \pm 0.8$ & 32 & $4.9 \pm 1.6$ & 0.255 \\
\hline Tryptophan ( $\mu \mathrm{mol} / \mathrm{L})$ & 24 & $51.2 \pm 7.7$ & 22 & $52.0 \pm 7.6$ & 32 & $52.8 \pm 8.1$ & 0.773 \\
\hline Kynurenine ( $\mu \mathrm{mol} / \mathrm{L})$ & 24 & $1.8 \pm 0.4$ & 22 & $2.0 \pm 0.6$ & 32 & $1.9 \pm 0.5$ & 0.277 \\
\hline $\mathrm{Kyn} / \operatorname{Trp}(\mu \mathrm{mol} / \mathrm{mmol})$ & 24 & $35.4 \pm 6.1$ & 22 & $39.3 \pm 10.0$ & 32 & $37.1 \pm 10.1$ & 0.361 \\
\hline Nitrite $(\mu \mathrm{mol})$ & 24 & $23.4 \pm 20.5$ & 22 & $16.5 \pm 12.3$ & 32 & $32.9 \pm 32.2$ & 0.112 \\
\hline$\% \mathrm{CD}^{+}$ & 40 & $75.5 \pm 8.9$ & 35 & $70.6 \pm 10.0$ & 38 & $68.9 \pm 12.9$ & 0.022 \\
\hline$\% \mathrm{CD}^{+}$ & 40 & $47.2 \pm 6.9$ & 35 & $46.6 \pm 8.8$ & 38 & $40.1 \pm 9.8$ & 0.001 \\
\hline$\% \mathrm{CD}^{+}$ & 40 & $26.0 \pm 9.5$ & 34 & $20.9 \pm 6.3$ & 38 & $26.6 \pm 11.2$ & 0.022 \\
\hline $\mathrm{CD}^{+} / \mathrm{CD}^{+}$ & 40 & $2.0 \pm 0.7$ & 34 & $2.4 \pm 0.8$ & 38 & $1.9 \pm 1.1$ & 0.037 \\
\hline$\% \mathrm{CD}^{+} 9^{+}$ & 40 & $8.8 \pm 6.9$ & 35 & $7.7 \pm 3.3$ & 38 & $7.2 \pm 3.6$ & 0.339 \\
\hline$\% \mathrm{CD}_{16}{ }^{+} 56^{+}$ & 40 & $13.7 \pm 6.8$ & 35 & $17.2 \pm 7.7$ & 38 & $20.2 \pm 11.9$ & 0.008 \\
\hline
\end{tabular}

a ANOVA test.

environmentally exposed group when compared to control females (MR $=0.60 ; 95 \%$ Cl 0.37-0.98).

The only notable but non-significant $(P=0.062)$ influence observed was that drinking bottled water was related to lower neopterin MR when compared to drinking tap water.

To quantitatively evaluate the immunotoxic effect of metal(loid) exposure on the selected biomarkers, we associated these latter data with metal(loid) concentrations in the biological matrices (blood, urine, finger and toenails, and hair) measured in the same subjects in the above mentioned study (Coelho et al., 2013). Subjects were divided according to the tertile distribution of each metal(loid) level in each biological matrix. Higher MRs for neopterin, kynurenine and Kyn/Trp were observed with increasing concentrations of $\mathrm{Pb}$ in toenails; significance was obtained for kynurenine in the 2nd and 3rd tertiles and for Kyn/Trp in the 3rd tertile, whereas the MR of neopterin in the 3rd tertile was borderline significant $(P=0.067)$ (Table 5). Levels of $\mathrm{Mn}$ in the 2nd tertile were significantly associated with decrease in $\% \mathrm{CD}^{+}$and increase in $\mathrm{CD} 4^{+} / \mathrm{CD}^{+}$ratio, and in the 3rd tertile with increase in $\mathrm{CD}^{+} / \mathrm{CD} 8^{+}$and decrease in \%CD19 ${ }^{+}$(Table 6 ).

We also investigated the presence of differences among groups concerning the report of symptoms related to metal(loid) intoxication (Table 7). Significant differences were obtained for cough with expectoration and taking medicines, with lower MR in both exposed groups. Moreover, as expected, significant influence of smoking was observed in cough with expectoration (higher MR in ever smokers) and of age in sick in recent years and taking medicines (higher MR in older individuals) (data not shown).

\section{Discussion}

Results from environmental geochemical campaigns performed in the proximity of the Panasqueira mine showed a high degree of contamination by several metal(loid)s in different media (Ávila et al., 2008; Ferreira da Silva et al., 2013; Grangeia et al., 2011; Salgueiro et al., 2008). Accordingly, biomonitoring studies carefully designed and carried out in local populations living near or working in the mine showed significantly higher concentrations of $\mathrm{As}, \mathrm{Cr}, \mathrm{Mg}, \mathrm{Mn}, \mathrm{Mo}, \mathrm{Pb}$ and $\mathrm{Zn}$ in blood, urine, nails and hair samples when compared to controls (Coelho et al., 2013). Preliminary data showed also immunotoxic effects in these populations (Coelho et al., 2011a, 2012). Therefore, a more robust study to evaluate the immunological alterations induced by this contamination was carried out, analysing a larger number of immunotoxicity biomarkers, including the levels of neopterin, tryptophan, kynurenine, nitrite, and percentages of several lymphocytes subsets. To our knowledge this is the first study in which these biomarkers were evaluated in human populations exposed to metal(loid)s resulting from mining activities both environmentally and occupationally.

Significant modifications of immunotoxicity parameters were observed in the exposed groups, specifically in the percentages of lymphocytes subsets (except for \%CD19 ${ }^{+}$). Lymphocytes are the primary cells involved in acquired immunity. They are highly specialized cells that interact with other cells to initiate immune response and the specificity of the receptor and functional heterogeneity allows them to respond to virtually any antigen (Descotes, 2004; Tryphonas et al., 2005). The importance of assessing changes in lymphocyte subsets is related to the

Table 3

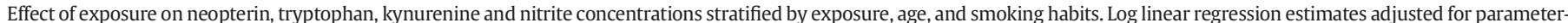
specific actual confounders.

\begin{tabular}{|c|c|c|c|c|c|c|c|c|c|c|}
\hline & \multicolumn{2}{|c|}{ Neopterin } & \multicolumn{2}{|c|}{ Tryptophan } & \multicolumn{2}{|c|}{ Kynurenine } & \multicolumn{2}{|c|}{ Kyn/Trp } & \multicolumn{2}{|c|}{ Nitrite } \\
\hline & MR & $95 \% \mathrm{CI}$ & MR & $95 \% \mathrm{CI}$ & MR & $95 \% \mathrm{CI}$ & MR & $95 \% \mathrm{CI}$ & MR & $95 \% \mathrm{CI}$ \\
\hline \multicolumn{11}{|l|}{ Exposure } \\
\hline Controls $(\mathrm{N}=40)$ & 1.00 & & 1.00 & & 1.00 & & 1.00 & & 1.00 & \\
\hline Env. exposed $(\mathrm{N}=41)$ & 1.02 & {$[0.90 ; 1.17]$} & 1.03 & {$[0.93 ; 1.14]$} & 1.11 & {$[0.95 ; 1.28]$} & 1.07 & {$[0.94 ; 1.23]$} & 0.73 & {$[0.43 ; 1.20]$} \\
\hline Occup. exposed $(\mathrm{N}=41)$ & 1.03 & {$[0.91 ; 1.17]$} & 1.03 & {$[0.94 ; 1.13]$} & 0.96 & {$[0.84 ; 1.11]$} & 0.93 & {$[0.82 ; 1.07]$} & 0.95 & {$[0.58 ; 1.56]$} \\
\hline \multicolumn{11}{|l|}{ Age (years) } \\
\hline $25-50(\mathrm{~N}=23)$ & 1.00 & & 1.00 & & 1.00 & & 1.00 & & 1.00 & \\
\hline $51-60(\mathrm{~N}=35)$ & 1.11 & {$[0.95 ; 1.30]$} & 1.02 & {$[0.90 ; 1.15]$} & $1.40^{* *}$ & {$[1.17 ; 1.69]$} & $1.38^{* *}$ & {$[1.16 ; 1.63]$} & 1.75 & {$[0.93 ; 3.31]$} \\
\hline $61-70(\mathrm{~N}=38)$ & $1.21^{*}$ & {$[1.03 ; 1.42]$} & 0.98 & {$[0.87 ; 1.11]$} & $1.28^{*}$ & {$[1.06 ; 1.55]$} & $1.31^{* *}$ & {$[1.10 ; 1.56]$} & 1.62 & {$[0.85 ; 3.08]$} \\
\hline$>71(\mathrm{~N}=26)$ & $1.44^{* *}$ & {$[1.21 ; 1.72]$} & 0.97 & {$[0.85 ; 1.11]$} & $1.59^{* *}$ & {$[1.30 ; 1.95]$} & $1.63^{* *}$ & {$[1.36 ; 1.97]$} & 1.33 & {$[0.67 ; 2.66]$} \\
\hline \multicolumn{11}{|l|}{ Smoking habits } \\
\hline Never smokers $(\mathrm{N}=73)$ & 1.00 & & 1.00 & & 1.00 & & 1.00 & & 1.00 & \\
\hline Ever smokers $(\mathrm{N}=49)$ & 1.11 & {$[0.99 ; 1.23]$} & 0.98 & {$[0.90 ; 1.06]$} & 1.00 & {$[0.88 ; 1.13]$} & 1.02 & {$[0.91 ; 1.14]$} & 1.19 & {$[0.78 ; 1.82]$} \\
\hline
\end{tabular}

Parameter-specific actual confounders: Neo - water consumption. No parameter-specific actual confounder was identified for Trp, Kyn, Kyn/Trp and nitrite.

$* P<0.05$.

** $P<0.01$. 
Table 4

Effect of exposure on lymphocytes subsets stratified by exposure, age, and smoking habits. Log linear regression estimates adjusted for parameter-specific actual confounders.

\begin{tabular}{|c|c|c|c|c|c|c|c|c|c|c|c|c|}
\hline & \multicolumn{2}{|c|}{$\% \mathrm{CD}^{+}$} & \multicolumn{2}{|l|}{$\% \mathrm{CD}^{+}$} & \multicolumn{2}{|c|}{$\% \mathrm{CD}^{+}$} & \multicolumn{2}{|c|}{$\mathrm{CD} 4^{+} / \mathrm{CD}^{+}$} & \multicolumn{2}{|c|}{$\% \mathrm{CD} 9^{+}$} & \multicolumn{2}{|c|}{$\% \mathrm{CD}_{16}{ }^{+} 56^{+}$} \\
\hline & MR & $95 \% \mathrm{CI}$ & MR & $95 \% \mathrm{CI}$ & MR & $95 \% \mathrm{CI}$ & MR & $95 \% \mathrm{CI}$ & MR & $95 \% \mathrm{CI}$ & MR & $95 \% \mathrm{CI}$ \\
\hline \multicolumn{13}{|l|}{ Exposure } \\
\hline Controls $(\mathrm{N}=40)$ & 1.00 & & 1.00 & & 1.00 & & 1.00 & & 1.00 & & 1.00 & \\
\hline Env. exposed $(\mathrm{N}=41)$ & 0.96 & {$[0.88 ; 1.04]$} & 1.00 & {$[0.90 ; 1.11]$} & $0.80^{*}$ & {$[0.67 ; 0.96]$} & $1.27^{*}$ & {$[1.02 ; 1.58]$} & 0.78 & {$[0.59 ; 1.02]$} & 1.29 & {$[0.99 ; 1.68]$} \\
\hline Occup. exposed $(\mathrm{N}=41)$ & $0.92^{*}$ & {$[0.85 ; 0.99]$} & $0.84^{* *}$ & {$[0.76 ; 0.93]$} & 0.96 & {$[0.79 ; 1.15]$} & 0.88 & {$[0.70 ; 1.11]$} & 0.92 & {$[0.69 ; 1.23]$} & $1.44^{* *}$ & {$[1.10 ; 1.88]$} \\
\hline \multicolumn{13}{|l|}{ Age (years) } \\
\hline $25-50(N=23)$ & 1.00 & & 1.00 & & 1.00 & & 1.00 & & 1.00 & & 1.00 & \\
\hline $51-60(\mathrm{~N}=35)$ & 0.97 & {$[0.88 ; 1.07]$} & 0.96 & {$[0.85 ; 1.09]$} & 0.98 & {$[0.79 ; 1.21]$} & 1.01 & {$[0.78 ; 1.30]$} & 0.79 & {$[0.58 ; 1.09]$} & 1.09 & {$[0.79 ; 1.50]$} \\
\hline $61-70(\mathrm{~N}=38)$ & $0.90^{*}$ & {$[0.82 ; 0.99]$} & 0.95 & {$[0.85 ; 1.07]$} & $0.79^{*}$ & {$[0.64 ; 0.98]$} & 1.23 & {$[0.96 ; 1.59]$} & 1.07 & {$[0.78 ; 1.46]$} & 1.33 & {$[0.98 ; 1.81]$} \\
\hline$>71(\mathrm{~N}=26)$ & 0.92 & {$[0.83 ; 1.03]$} & 0.90 & {$[0.79 ; 1.02]$} & 0.98 & {$[0.71 ; 1.12]$} & 1.02 & {$[0.77 ; 1.33]$} & $0.71^{*}$ & {$[0.51 ; 0.99]$} & 1.31 & {$[0.94 ; 1.82]$} \\
\hline \multicolumn{13}{|l|}{ Smoking habits } \\
\hline Never smokers $(N=73)$ & 1.00 & & 1.00 & & 1.00 & & 1.00 & & 1.00 & & 1.00 & \\
\hline Ever smokers $(\mathrm{N}=49)$ & 0.99 & {$[0.93 ; 1.07]$} & 1.04 & {$[0.95 ; 1.13]$} & 1.02 & {$[0.87 ; 1.20]$} & 0.98 & {$[0.81 ; 1.19]$} & 0.87 & {$[0.70 ; 1.09]$} & 0.93 & {$[0.74 ; 1.16]$} \\
\hline
\end{tabular}

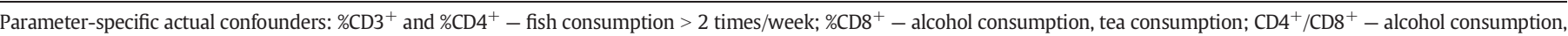
tea consumption, fish consumption $>2$ times/week; \%CD9 ${ }^{+}-$tea consumption, fish consumption $>2$ times/week, surgery in recent years; \%CD16 ${ }^{+} 56^{+}-$surgery in recent years.

$* P<0.05$.

** $P<0.01$.

existing evidence linking these changes to exposure to immunotoxic compounds and consequently to alterations of the immune response (Biró et al., 2002; Boscolo et al., 1999; Oh et al., 2005; Tulinska et al., 2004). Hernandez-Castro et al. (2009) demonstrated that an increased, diminished, or absent function of immune-system cells is clearly associated with autoimmune diseases, deregulation of the immune response, and defective immune response against neoplastic cells or different pathogens. The effect of exposure on the different lymphocyte subsets varied according to the source of exposure: the environmentally exposed group showed alterations in $\% \mathrm{CD}^{+}$and $\mathrm{CD} 4^{+} / \mathrm{CD}^{+}$ratio, while mine workers in $\% \mathrm{CD}^{+}, \% \mathrm{CD}^{+}$and $\% \mathrm{CD}^{+} 6^{+} 56^{+}$(Table 4 ). As described in Coelho et al. (2013), the environmentally exposed group experienced a pronounced and continuous (past and recent) exposure to As, a moderate but continuous exposure to $\mathrm{Mg}$, $\mathrm{Mn}$ and $\mathrm{Zn}$, a recent exposure to Mo and past exposure to $\mathrm{Cr}, \mathrm{Ni}$ and $\mathrm{S}$. On the contrary, the occupationally exposed group experienced a continuous exposure to $\mathrm{Zn}$, recent exposure to Se, and long standing exposure to As, Mn and $\mathrm{Pb}$. When we evaluated the immunotoxic effects in the study individuals according to the tertile distribution of metal(loid) concentrations in their biological samples, significant results were obtained for $\mathrm{Pb}$ in toenails (Table 5) and Mn in blood (Table 6). Considering all this information, our results seem to point to occupational exposure to $\mathrm{Pb}$ and environmental and occupational exposure to $\mathrm{Mn}$ as the main conditions inducing immunotoxic effects in the study populations.

Exposure to $\mathrm{Pb}$ has been shown to adversely affect several immune functions (Chen et al., 2004; Luebke et al., 2006), although the exact mechanism by which this happens is still unclear (García-Lestón et al., 2012). In our study high levels of $\mathrm{Pb}$ (2nd and 3rd tertile with mean concentrations of 0.68 and $2.43 \mu \mathrm{g} / \mathrm{g}$, respectively) in toenails increased the MR of neopterin, kynurenine and Kyn/Trp. Nevertheless, when exposed populations were compared to controls these parameters did not show significant modifications, so it seems that other factors, different from the place of living or the occupation, influence the plasma concentration of neopterin and kynurenine. Different results were obtained by García-Lestón et al. (2012), who found significantly higher concentrations of tryptophan and significantly lower levels of Kyn/Trp, with no alteration in neopterin levels, in individuals occupationally exposed to $\mathrm{Pb}$. These latter findings concerning neopterin concentrations were confirmed by Engin et al. (2006) in a population with similar exposure. However, it should be taken into account that in the current study exposure was not restricted to $\mathrm{Pb}$ but a complex mixture of metal(loid)s had to be considered.

Neopterin is produced by monocyte-derived macrophages as a result of interferon- $\gamma$ (IFN $\gamma$ ) stimulation within the activation of cellmediated immune response (Weiss et al., 1999). The degradation of tryptophan to form kynurenine is also promoted by IFN $\gamma$ (Taylor and Feng, 1991). Accelerated tryptophan breakdown, and consequently elevated Kyn/Trp ratio in serum/plasma, has been shown to strongly correlate with neopterin concentrations (Schroecksnadel et al., 2006). This mechanism was confirmed in our study since significant correlations were obtained between these parameters, although only minor increases were found in the exposed groups vs. non-exposed (Table 2). Furthermore, our results seem to confirm the presence of an inflammatory background of these metabolic alterations, arguing against a primary role of the liver enzyme tryptophan pyrrolase. In humans, an increased formation of neopterin and enhanced breakdown of tryptophan have been found in viral infections, malignant disorders and autoimmune diseases (Schroecksnadel et al., 2006). Besides, neopterin concentration and Kyn/Trp ratio provide significant predictive information in patients with various diseases like cardiovascular disease (Pedersen et al., 2011), several forms of cancer (Sucher et al., 2010) and/or with infections and sepsis (Schroecksnadel et al., 2006).

Table 5

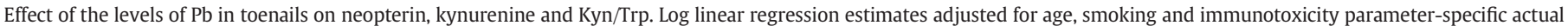
confounders.

\begin{tabular}{|c|c|c|c|c|c|c|}
\hline \multirow[t]{2}{*}{$\mathrm{Pb}$ in toenails (mean $\pm \mathrm{SD}$ ) } & \multicolumn{2}{|c|}{ Neopterin } & \multicolumn{2}{|c|}{ Kynurenine } & \multicolumn{2}{|c|}{ Kyn/Trp } \\
\hline & MR & $95 \% \mathrm{CI}$ & MR & $95 \% \mathrm{CI}$ & MR & $95 \% \mathrm{CI}$ \\
\hline $\begin{array}{l}\text { 1st tertile } \\
\quad(0.32 \pm 0.09)\end{array}$ & 1.00 & & 1.00 & & 1.00 & \\
\hline $\begin{array}{l}\text { 2nd tertile } \\
\qquad(0.68 \pm 0.16)\end{array}$ & 1.10 & {$[0.97 ; 1.24]$} & $1.25^{*}$ & {$[1.07 ; 1.47]$} & 1.08 & {$[0.95 ; 1.23]$} \\
\hline $\begin{array}{l}\text { 3rd tertile } \\
\qquad(2.43 \pm 1.51)\end{array}$ & 1.12 & {$[0.99 ; 1.26]$} & $1.34^{*}$ & {$[1.16 ; 1.56]$} & $1.28^{*}$ & {$[1.14 ; 1.44]$} \\
\hline
\end{tabular}

Values presented for each tertile are expressed in $\mu \mathrm{g} / \mathrm{g}$.

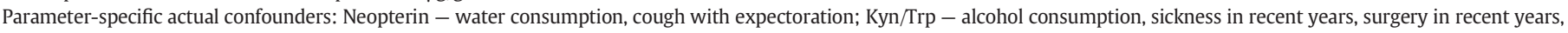
agricultural work, water consumption. No parameter-specific actual confounder was identified for kynurenine.

* $P<0.01$. 
Table 6

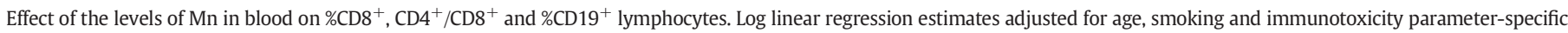
actual confounders.

\begin{tabular}{|c|c|c|c|c|c|c|}
\hline \multirow[t]{2}{*}{ Mn in blood (mean $\pm S D$ ) } & \multicolumn{2}{|c|}{$\% \mathrm{CD}^{+}$} & \multicolumn{2}{|c|}{$\mathrm{CD}^{+} / \mathrm{CD}^{+}$} & \multicolumn{2}{|c|}{$\% \mathrm{CD} 19^{+}$} \\
\hline & MR & $95 \% \mathrm{CI}$ & MR & $95 \% \mathrm{CI}$ & MR & $95 \% \mathrm{CI}$ \\
\hline $\begin{array}{l}\text { 1st tertile } \\
\qquad(14.09 \pm 2.00)\end{array}$ & 1.00 & & 1.00 & & 1.00 & \\
\hline $\begin{array}{l}\text { 2nd tertile } \\
\qquad(18.56 \pm 1.22)\end{array}$ & $0.82^{*}$ & {$[0.68 ; 0.97]$} & $1.33^{*}$ & {$[1.07 ; 1.65]$} & 0.98 & {$[0.70 ; 1.37]$} \\
\hline $\begin{array}{l}\text { 3rd tertile } \\
\qquad(36.09 \pm 38.45)\end{array}$ & 0.87 & {$[0.72 ; 1.05]$} & $1.28^{*}$ & {$[1.03 ; 1.59]$} & $0.71^{*}$ & {$[0.51 ; 0.99]$} \\
\hline
\end{tabular}

Values presented for each tertile are expressed in $\mu \mathrm{g} / \mathrm{L}$.

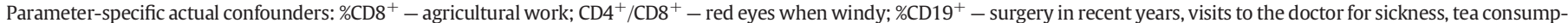
tion, taking medicines, fish consumption $>2$ times/week, water consumption, sickness in recent years.

$* \quad P<0.05$.

In our study high levels of Mn (2nd and 3rd tertile with mean concentrations of 18.56 and $36.09 \mu \mathrm{g} / \mathrm{L}$, respectively) in blood decrease the $\mathrm{MR}$ of $\% \mathrm{CD} 8^{+}$and \%CD19 ${ }^{+}$and increased the $\mathrm{MR}$ of $\mathrm{CD} 4^{+} / \mathrm{CD}^{+}$ ratio. The influence of $\mathrm{Mn}$ on the immune system is still unclear, as confirmed by the conflicting results reported in the literature; some studies in animals and human populations demonstrated immunotoxic effects (Antonini et al., 2012; Nakata et al., 2006), not confirmed by others (Yuan et al., 2006). Our results are in agreement with those obtained by Nakata et al. (2006) who observed a significant decrease in \%CD8 ${ }^{+}$ and \%CD19 ${ }^{+}$associated with exposure to Mn fumes in the groups with higher (mean concentration of $17 \mu \mathrm{g} / \mathrm{L}$ ) and moderate (mean value of $11 \mu \mathrm{g} / \mathrm{L}$ ) levels of $\mathrm{Mn}$ in blood.

Immunological biomarkers analysed in the present study appeared to be influenced by host factors, such as age and gender. The effect of age in the immune system has been described in several reports (Knight, 2000; Schindowski et al., 2002; Wick et al., 1997). Ageing is associated with a defective function of the immune system, which can lead to infections, autoimmune diseases, and cardiovascular or neurodegenerative disorders (Frick et al., 2004). In our study population older individuals presented increased levels of neopterin, kynurenine and Kyn/Trp ratio. Similar results were published by several groups (Diamondstone et al., 1994; Frick et al., 2004; García-Lestón et al., 2012; Spencer et al., 2010). Increased neopterin concentrations and $\mathrm{Kyn} / \mathrm{Trp}$ ratio in older healthy people were suggested to be associated with immune activation (Frick et al., 2004). We also found older individuals having lower levels of $\% \mathrm{CD}^{+}, \% \mathrm{CD} 8^{+}$and $\% \mathrm{CD} 19^{+}$, similarly to many other publications on similar topics (Chng et al., 2004; Coelho et al., 2011a, 2012; Jentsch-Ullrich et al., 2005; Sansoni et al., 1993; Shahabuddin et al., 1998). The robust consistency of results from the Panasqueira study concerning the effect of ageing with evidence existing in the literature provides an intrinsic validation of our results.

The significant influence of gender on $\% \mathrm{CD} 19^{+}$(in our study this effect is combined with exposure) was also described in other studies, with females generally presenting higher values (Abdullah et al., 2012; Chng et al., 2004). Remarkably, the variations in the immune system related to age and gender have been linked to several diseases such as autoimmune disorders in females and leukaemia or lymphoma in males and elderly individuals (Jentsch-Ullrich et al., 2005).

From all the clinical symptoms evaluated in the exposed populations, cough with expectoration and taking medicines significantly differ among study populations. The significant decrease observed in these symptoms in the occupationally exposed group may be explained by the "Healthy Worker Effect". According to this concept, working individuals have a lower morbidity when compared to the rest of the population as healthier individuals are more likely to get employment and remain employed (Thygesen et al., 2011). As regards the decrease in taking medicines in the occupationally exposed group, this unexpected finding can be related to a higher prevalence of males in this group; usually females go to the doctor and take medicines more frequently than males.

\section{Conclusions}

Overall, the results of this study agree with those obtained in the preliminary studies (Coelho et al., 2011a, 2012), revealing immunotoxic effects experienced by populations environmentally and occupationally exposed to the metal(loid) contamination derived from the Panasqueira mining activities. The level of most exposure biomarkers was quantitatively associated with the intensity of immunotoxic effects. The immunological alterations observed may significantly increase the risk of developing immunological pathologies, and thus there is an urgent need for intervention in the area by the competent authorities to protect the health of populations working and living near the mine.

\section{Acknowledgements}

This work was supported by the Portuguese Foundation for Science and Technology under the grant SFRH/BD/47781/2008 and the project PTDC/SAU-ESA/102367/2008, and by the European Commission (ERA NET - New INDIGO Program, NanoLINEN project, PIM2010ENI00632). The work of Roberto Zoffoli, Valentina Dall'Armi, and Stefano

Table 7

Logistic regression analysis for symptoms. Adjustment for age, smoking and symptom-specific actual confounders.

\begin{tabular}{|c|c|c|c|c|c|c|c|c|c|c|c|c|c|c|c|c|}
\hline & \multicolumn{2}{|c|}{$\begin{array}{l}\text { Cough with } \\
\text { expectoration }\end{array}$} & \multicolumn{2}{|c|}{$\begin{array}{l}\text { Alterations in } \\
\text { skin }\end{array}$} & \multicolumn{2}{|c|}{$\begin{array}{l}\text { Alterations in } \\
\text { smell }\end{array}$} & \multicolumn{2}{|c|}{$\begin{array}{l}\text { Alterations in } \\
\text { taste }\end{array}$} & \multicolumn{2}{|c|}{$\begin{array}{l}\text { Red eyes when } \\
\text { windy }\end{array}$} & \multicolumn{2}{|c|}{$\begin{array}{l}\text { Sick in recent } \\
\text { years }\end{array}$} & \multicolumn{2}{|c|}{$\begin{array}{l}\text { Visits to doctor - } \\
\text { sickness }\end{array}$} & \multicolumn{2}{|c|}{ Taking medicines } \\
\hline & MR & $95 \% \mathrm{CI}$ & MR & $95 \% \mathrm{CI}$ & MR & $95 \% \mathrm{CI}$ & MR & $95 \% \mathrm{CI}$ & MR & $95 \% \mathrm{CI}$ & MR & $95 \% \mathrm{CI}$ & MR & $95 \% \mathrm{CI}$ & MR & $95 \% \mathrm{CI}$ \\
\hline Controls $(\mathrm{N}=40)$ & 1.00 & & 1.00 & & 1.00 & & 1.00 & & 1.00 & & 1.00 & & 1.00 & & 1.00 & \\
\hline $\begin{array}{l}\text { Env. exposed } \\
\qquad(\mathrm{N}=41)\end{array}$ & $0.27^{*}$ & {$[0.09 ; 0.82]$} & 0.69 & {$[0.15 ; 3.06]$} & 0.37 & {$[0.05 ; 2.50]$} & 0.48 & {$[0.05 ; 5.21]$} & 1.75 & {$[0.64 ; 4.83]$} & 0.97 & {$[0.36 ; 2.64]$} & 1.27 & {$[0.47 ; 3.41]$} & 0.52 & {$[0.13 ; 2.00]$} \\
\hline $\begin{array}{l}\text { Occup. exposed } \\
\quad(\mathrm{N}=41)\end{array}$ & $0.31^{*}$ & {$[0.10 ; 0.93]$} & 0.33 & {$[0.05 ; 2.05]$} & 0.68 & {$[0.15 ; 3.08]$} & 0.37 & {$[0.04 ; 3.68]$} & 0.50 & {$[0.19 ; 1.34]$} & 0.62 & {$[0.23 ; 1.72]$} & 0.38 & {$[0.14 ; 1.06]$} & $0.22^{*}$ & {$[0.06 ; 0.85]$} \\
\hline
\end{tabular}

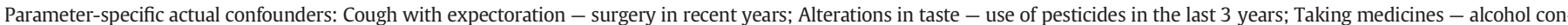

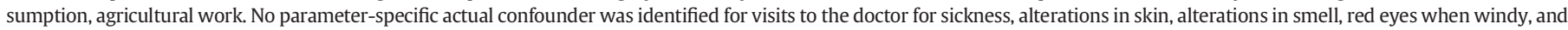
sickness in recent years.

* $P<0.05$. 
Bonassi was supported by grants funded by the Associazione Italiana per la Ricerca sul Cancro (AIRC).

\section{Conflict of interest}

The authors declare that they have no conflicts of interest.

\section{References}

Abdullah M, Chai PS, Chong MY, Tohit ER, Ramasamy R, Pei CP, et al. Gender effect on in vitro lymphocyte subset levels of healthy individuals. Cell Immunol 2012;272:214-9.

Antonini JM, Zeidler-Erdely PC, Young SH, Roberts JR, Erdely A. Systemic immune cell response in rats after pulmonary exposure to manganese-containing particles collected from welding aerosols. J Immunotoxicol 2012;9:184-92.

Ávila P, Silva E, Salgueiro A, Farinha J. Geochemistry and mineralogy of mill tailings impoundments from the Panasqueira mine (Portugal): implications for the surrounding environment. Mine Water Environ 2008;27:210-24.

Biró A, Pállinger E, Major J, Jakab MG, Klupp T, Falus A, et al. Lymphocyte phenotype analysis and chromosome aberration frequency of workers occupationally exposed to styrene, benzene, polycyclic aromatic hydrocarbons or mixed solvents. Immunol Lett 2002:81:133-40.

Blank JA, Luster MI, Langone JJ, Wilson SD. Immunotoxicology - regulatory and risk assessment concepts. Int J Toxicol 2000;19:95-106.

Boscolo P, Di Gioacchino M, Sabbioni E, Benvenuti F, Conti P, Reale M, et al. Expression of lymphocyte subpopulations, cytokine serum levels, and blood and urinary trace elements in asymptomatic atopic men exposed to an urban environment. Int Arch Occup Environ Health 1999; 72:26-32.

Cabassi E. The immune system and exposure to xenobiotics in animals. Vet Res Commun 2007;31:115-20.

Capuron L, Moranis A, Combe N, Cousson-Gelie F, Fuchs D, De Smedt-Peyrusse V, et al. Vitamin $\mathrm{E}$ status and quality of life in the elderly: influence of inflammatory processes. Br J Nutr 2009;102:1390-4.

Capuron L, Schroecksnadel S, Féart C, Aubert A, Higueret D, Barberger-Gateau P, et al. Chronic low-grade inflammation in elderly persons is associated with altered tryptophan and tyrosine metabolism: role in neuropsychiatric symptoms. Biol Psychiatry 2011;70: $175-82$.

Chen S, Golemboski KA, Piepenbrink M, Dietert RR. Developmental immunotoxicity of lead in the rat: influence of maternal diet. J Toxicol Environ Health A 2004:67:495-511.

Chng WC, Tan GB, Kuperan P. Establishment of adult peripheral blood lymphocyte subset reference range for an Asian population by single platform flow cytometry: influence of age, sex and race and comparison with other published studies. Clin Diagn Lab Immunol 2004:11:168-73.

Coelho P, Costa S, Costa C, Silva S, Walter A, Ranville J, et al. Biomonitoring of several toxic metal(loid)s in different biological matrices from environmentally and occupationally exposed populations from Panasqueira mine area - Portugal. Environ Geochem Health 2013. http://dx.doi.org/10.1007/s10653-013-9562-7.

Coelho P, Costa S, Silva S, Walter A, Ranville J, Sousa AC, et al. Metal(loid)s levels in biological matrices from human populations exposed to mining contamination Panasqueira mine (Portugal). J Toxicol Environ Health A 2012;75:893-908.

Coelho P, García-Lestón J, Silva S, Costa C, Costa S, Coelho M. Geno- and immunotoxic effects on populations living near a mine - case study: Panasqueira mine. J Toxicol Environ Health A 2011a:74:1076-86.

Coelho P, Teixeira JP, Gonçalves O. Mining activities: health impacts. In: Nriagu JO, editor. Encyclopedia of environmental health. Burlington: Elsevier; 2011b. p. 788-802.

Descotes J. Classification of immunotoxicants. Immunotoxicology of drugs and chemicals: an experimental approach. Principles and methods of immunotoxicologyAmsterdam: Elsevier; 2004. p. 379-85.

Diamondstone LS, Tollerud DJ, Fuchs D, Wachter H, Brown LM, Maloney E, et al. Factors influencing serum neopterin and beta 2-microglobulin levels in a healthy diverse population. J Clin Immunol 1994;14:368-74.

Engin AB, Tuzun D, Sahin G. Evaluation of pteridine metabolism in battery workers chronically exposed to lead. Hum Exp Toxicol 2006;25:353-9.

Ferreira da Silva E, Ávila PF, Salgueiro AR, Candeias C, Garcia Pereira H, Quantitativespatial assessment of soil contamination in S. Francisco de Assis due to mining activity of the Panasqueira mine (Portugal)Environ Sci Pollut Res 2013. http:// dx.doi.org/10.1007/s11356-013-1495-2. [online 31 January 2013].

Frick B, Schroecksnadel K, Neurauter G, Leblhuber F, Fuchs D. Increasing production of homocysteine and neopterin and degradation of tryptophan with older age. Clin Biochem 2004:37:684-7.

García-Lestón J, Roma-Torres J, Mayan O, Schroecksnade S, Fuchs D, Moreira A, et al. Assessment of immunotoxicity parameters in individuals occupationally exposed to lead. J Toxicol Environ Health A 2012;75:807-18.

García-Lestón J, Roma-Torres J, Vilares M, Pinto R, Cunha L, Prista J, et al. Biomonitoring of a population of Portuguese workers exposed to lead. Mutat Res 2011;721:81-8.
Grangeia C, Ávila P, Matias M, Ferreira da Silva E. Mine tailings integrated investigations: the case of Rio tailings (Panasqueira Mine, Central Portugal). Eng Geol 2011;123: 359-72.

Griess P. Bemerkungen zu der Abhandlung der HH. Weselky und Benedikt "Ueber einige Azoverbindungen". Chemistry 1879;12:426-8.

Henkler F, Brinkmann J, Luch A. The role of oxidative stress in carcinogenesis induced by metals and xenobiotics. Cancers 2010;2:376-96.

Hernandez-Castro B, Doniz-Padilla LM, Salgado-Bustamante M, Rocha D, Ortiz-Perez MD, Jimenez-Capdeville ME, et al. Effect of arsenic on regulatory T cells. J Clin Immunol 2009;29:461-9.

Jentsch-Ullrich K, Koenigsmann M, Mohren M, Franke A. Lymphocyte subsets' reference ranges in an age and gender-balanced population of 100 healthy adults - a monocentric German study. Clin Immunol 2005;116:192-7.

Knight JA. Review: free radicals, antioxidants and immune system. Ann Clin Lab Sci 2000;30:145-58.

Lehmann I, Sack U, Lehmann J. Metal ions affecting the immune system. In: Sigel A, Sigel $\mathrm{H}$, Sigel RKO, editors. Metal ions in toxicology: effects, interactions, interdependencies. Cambridge, UK: The Royal Society of Chemistry; 2011. p. 157-85.

Luebke RW, Chen DH, Dietert R, Yang Y, King M, Luster MI. The comparative immunotoxicity of five selected compounds following developmental or adult exposure. J Toxicol Environ Health B Crit Rev 2006;9:1-26.

Mudgal V, Madaan N, Mudgal A, Singh R, Mishra S. Toxic metals on human health. Open Nutraceuticals J 2010;3:94-9.

Nakata A, Araki S, Park S-H, Park J-T, Kim D-S, Park H-C, et al. Decreases in CD8 ${ }^{+}$T, naive $\left(\mathrm{CD} 4^{+} \mathrm{CD}^{2} 5 \mathrm{RA}^{+}\right) \mathrm{T}$, and $\mathrm{B}\left(\mathrm{CD} 19^{+}\right)$lymphocytes by exposure to manganese fume. Ind Health 2006:44:592-7.

Oh E, Lee E, Im H, Kang H-S, Jung W-W, Won NH, et al. Evaluation of immuno- and reproductive toxicities and association between immunotoxicological and genotoxicological parameters in waste incineration workers. Toxicology 2005;210:65-80.

Pedersen ER, Midttun Ø, Ueland PM, Schartum-Hansen H, Seifert R, Igland J, et al. Systemic markers of interferon-a-mediated immune activation and long-term prognosis in patients with stable coronary artery disease. Arterioscler Thromb Vasc Biol 2011;31:698-704

Salgueiro A, Avila P, Pereira H, Silva E. Assessment of the impact of pollution by arsenic in the vicinity of Panasqueira mine (Portugal). In: Atkinson PM, Lloyd CD, editors. geoENV VII - geostatistics for environmental applications: proceedings of the Seventh European Conference on Geostatistics for Environmental Applications, 8-10 September 2008. Southampton, UK: Springer-Verlag; 2008. p. 151-60.

Sansoni P, Cossarizza A, Brianti V, Fagnoni F, Snelli G, Monti D, et al. Lymphocyte subsets and natural killer cell activity in healthy old people and centenarians. Blood 1993;82: 2767-73.

Shahabuddin S, Al-Ayedi I, Gad El-Rab MO, Qureshi MI. Age-related changes in blood lymphocyte subsets of Saudi Arabian healthy children. Clin Diagn Lab Immunol 1998;5: 632-5.

Schindowski K, Frohlich L, Maurer K, Muller WE, Eckert A. Age related impairment of human T lymphocytes' activation: specific differences between CD4(+) andCD8(+) subsets. Mech Ageing Dev 2002;123:375-90.

Schroecksnadel K, Wirleitner B, Winkler C, Fuchs D. Monitoring tryptophan metabolism in chronic immune activation. Clin Chim Acta 2006;364:82-90.

Spencer ME, Jain A, Matteini A, Beamer BA, Wang NY, Leng SX, et al. Serum levels of the immune activation marker neopterin change with age and gender and are modified by race, BMI, and percentage of body fat. J Gerontol A Biol Sci Med Sci 2010;65:858-65.

Sucher R, Schroecksnadel K, Weiss G, Margreiter R, Fuchs D, Brandacher G. Neopterin, a prognostic marker in human malignancies. Cancer Lett 2010;287:13-22.

Taylor MW, Feng GS. Relationship between interferon-gamma, indoleamine 2,3-dioxygenase, and tryptophan catabolism. FASEB J 1991;5:2516-22.

Thygesen LC, Hvidtfeldt UA, Mikkelsen S, Bronnum-Hansen H. Quantification of the healthy worker effect: a nationwide cohort among electricians in Denmark. BMC Public Health 2011;11:571.

Tryphonas H, Fournier M, Blakley B, Smits J, Brousseau P. Structural and functional complexity of the immune system and its relationship to immunotoxicology. In: Blakley $\mathrm{BR}$, Kouassi E, editors. Investigative immunotoxicology. Boca Raton: Taylor and Francis; 2005. p. 3-10.

Tulinska J, Jahnova E, Dusinska M, Kuricova M, Liskova A, Ilavska S. Immunomodulatory effects of mineral fibres in occupationally exposed workers. Mutat Res 2004;553:111-24.

Weiss G, Murr C, Zoller H, Haun M, Winder B, Ludescher C, et al. Modulation of neopterin formation and tryptophan degradation by Th1- and Th2-derived cytokines in human monocytic cells. Clin Exp Immunol 1999;116:435-40.

Wick G, Romen M, Amberger A, Metzler B, Mayr M, Falkensammer G, et al. Atherosclerosis, autoimmunity, and vascular-associated lymphoid tissue. FASEB J 1997:11:1199-207.

Widner B, Werner ER, Schennach H, Wachter H, Fuchs D. Simultaneous measurement of serum tryptophan and kynurenine by HPLC. Clin Chem 1997;43:2424-6.

Yuan H, He S, He M, Niu Q, Wang L, Wang S. A comprehensive study on neurobehavior, neurotransmitters and lymphocyte subsets alteration of Chinese manganese welding workers. Life Sci 2006;78:1324-8. 